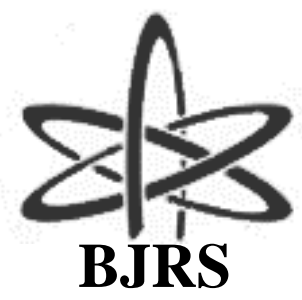

BRAZILIAN JOURNAL

$\mathrm{OF}$

RADIATION SCIENCES

09-02 (2021) 01-17

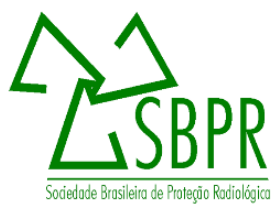

\title{
11-year workload and barrier analysis for a high-energy linear accelerator
}

\author{
Rigo $^{a}$ I.R., Cunha ${ }^{\mathrm{b}}$ A.P.V., Emiliozzi ${ }^{\mathrm{b}}$ C.Z.S., Menegussi ${ }^{\mathrm{b}}$ G.. \\ ${ }^{a}$ Faculdade de Medicina FMUSP, Universidade de São Paulo, 01246-903, São Paulo, São Paulo, Brazil \\ ${ }^{b}$ Departamento de Radiologia e Oncologia, Hospital das Clínicas HCFMUSP, Faculdade de Medicina, Universidade \\ de São Paulo, 05403-010, São Paulo, São Paulo, Brazil \\ isabela.rigo36@gmail.com
}

\section{ABSTRACT}

The formalism used for barriers calculations is based on a conservative estimation of workload, use factor, and occupancy factor. IMRT techniques (Intensity Modulated Radiation Therapy) and VMAT (Volumetric Modulated Arc Therapy) are known for being superior to conventional techniques, but costly from the shielding standpoint, as they increase the number of monitor units used to deliver the same dose to the patient, increasing the leakage radiation produced and, consequently, the thickness of the secondary barriers. At InRad (Radiology Institute of HC-FMUSP) a 2100CD LINAC already installed was upgraded to perform IMRT/VMAT techniques, and the existing barrier was reassessed. The present study proposes a methodology for acquiring real workload data from the institution's management software (MOSAIQ $\left.{ }^{\circledR}\right)$ to replace the initially estimated data and recalculate the thickness of the barriers, assessing the impact of the introduction of these techniques and understanding the profile of the treatments carried out at the institution over the years of 2010 to 2020 . Through this methodology, a decrease in the workload of $15 \mathrm{MV}$ was observed as the technique of modulated intensity with $6 \mathrm{MV}$ was introduced, reducing the thicknesses calculated for primary barriers. However, no significant changes were observed in the thicknesses calculated for the secondary barriers, because despite the increase in the leakage workload of $6 \mathrm{MV}$, the total workload of $15 \mathrm{MV}$ decreased. There was also a trend towards an increase in the number of patients treated with modulated intensity year after year, which went from $5 \%$ in 2016 to $67 \%$ in 2020. 


\section{INTRODUCTION}

The concern with the damage caused by ionizing radiation in the human body is one of the main pillars of radioprotection and therefore, maximum dose values are established, both for occupationally exposed individuals (OEI) and for the general public, in order to limit exposure to levels as low as reasonably achievable. Thus, practices that use ionizing radiation, such as radiotherapy, must ensure compliance with the limits authorized by the responsible organization CNEN (National Nuclear Energy Commission) in Brazil and with the optimization principle. To achieve those goals shielding is fundamental so, the thickness of the walls, ceiling, floor, and doors, in addition to the labyrinth extension of a radiotherapy room are calculated based on international recommendations (reports 49 and 151 of the NCRP [1,2]).

Radiation therapy produces direct, leakage and scattered radiation. Although superior in terms of conformity, IMRT (Intensity Modulated Radiation Therapy) technique is considered costly from the shielding standpoint since more monitor units are used to deliver the same dose to the patient. This happens because only a small fraction of each treatment field is irradiated at every moment, which promotes an increase in leakage radiation and consequently, an increase in the thickness of secondary barriers. As can be seen in figure 1, secondary barriers are the ones not directly irradiated by the beam, only by leakage and scattered radiation. The thickness of the primary barrier should not change if the average doses administered per patient are the same. [2-7]

The 2100CD LINAC at Inrad (Radiology Institute of HC-FMUSP) uses $6 \mathrm{MV}$ and $15 \mathrm{MV}$ for photons and $6 \mathrm{MeV}, 9 \mathrm{MeV}, 12 \mathrm{MeV}$, and $15 \mathrm{MeV}$ for electrons. That machine was upgraded to perform modulated techniques, such as IMRT and VMAT with $6 \mathrm{MV}$ and as a result, the profile of treatments changed, increasing the percentage of modulated techniques. This modernization triggered a need of reassessing the existing barrier, since at the same time that the increase in monitor units promotes the increase of the thickness of the secondary barriers, the decrease in the number of treatments performed with high-energy $(15 \mathrm{MV})$ promotes a reduction in the thickness of all barriers. [2]

Currently, the data obtained in the radiometric survey suggest that the barriers are adequate for the treatments carried out at the institution. However, such verification is done based on the 
workload initially estimated in the barriers calculation, and, besides, it is also known that the calculation formalism is conservative and, usually, the thickness of the shielding is overestimated. Therefore, there is an interest in knowing the current workload for each energy and the variation that occurred after the IMRT/VMAT techniques were implemented.

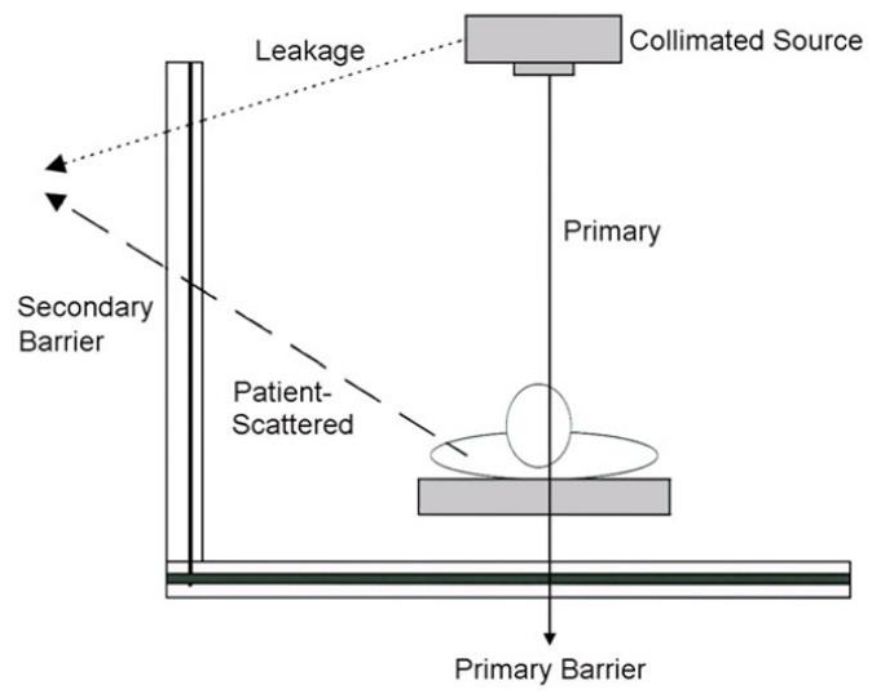

Figure 1: Illustration of primary and secondary barriers in a treatment room.

Source: NCRP 151 [2], with permission of the National Council on Radiation Protection and Measurements, https://NCRPonline.org.

\section{MATERIALS AND METHODS}

\subsection{Data Acquisition}

Clinical workload data was acquired through automatically generated reports by the MOSAIQ® (Elekta, Stockholm-Sweden) management software, making it possible to extract the technique and energy used to deliver the treatment, in addition to the dose received at the isocenter and the monitor units delivered to each patient in each treatment session.

Furthermore, information related to activities under the responsibility of the medical physics group, such as patient-specific quality assurance and tests frequently performed (picket fence) were also acquired using the management software. The other tasks performed without the aid of MOSAIQ ${ }^{\circledR}$ were estimated using the monthly, quarterly, and annual reports of monitor units, in 
addition to those used for commissioning and acceptance, making it possible to estimate the physical workload.

As a result, the physical workload was divided into three components:

- Data from the management software related to the patient-specific quality assurance and picket fence. These data for the $2100 \mathrm{CD}$ exist only after the upgrade, since before the accelerator was not enabled to perform modulated techniques and such tests were not done. Thus, the accelerator initially received the name $2100 \mathrm{C}$ and after the upgrade changed to $2100 \mathrm{CD}$;

- Dosimetry, quality assurance, and maintenance data of the linear accelerator were estimated based on the schedule of daily, monthly, quarterly and annual tests performed at the institution and considering that $20 \%$ of the measurements are repeated;

- Acceptance and commissioning data were estimated based on the manufacture mandatory tests, considering an accelerator life of twenty years (one commissioning every five years [7]) and also that $20 \%$ of the measurements are repeated.

\subsection{Barriers Calculation}

\subsubsection{Concepts Definition}

To calculate the thickness of the barriers, some concepts must be defined, according to NCRP $151[2]:$

Workload (W): Weekly absorbed dose at the isocenter. It can be defined separately for the different radiation sources: direct $\left(\mathrm{W}_{\mathrm{dir}}\right)$, scattered $\left(\mathrm{W}_{\mathrm{sca}}\right)$, and leakage $\left(\mathrm{W}_{\text {leak }}\right)$ and depends on the treatment technique (whether conventional or special, such as modulated treatments).

- $\mathrm{W}_{\text {dir: }}$ Sum of contributions from procedures or activities, which produce direct incidence of radiation of quality QX on some primary barrier. [3]

$$
\mathrm{W}_{\text {dir }}(\mathrm{QX})=\mathrm{W}_{\mathrm{D}, \mathrm{conv}}(\mathrm{QX})+\mathrm{W}_{\mathrm{D}, \bmod }(\mathrm{QX})+\mathrm{W}_{\mathrm{D}, \mathrm{phy}}(\mathrm{QX})
$$

Where $\mathrm{W}_{\mathrm{D} \text {,conv }}(\mathrm{QX})$ is the dose delivered with conventional techniques (2D and 3D), $\mathrm{W}_{\mathrm{D} \text {,mod }}(\mathrm{QX})$ is the dose delivered with modulated techniques (IMRT/VMAT), and $\mathrm{W}_{\mathrm{D} \text {,phy }}(\mathrm{QX})$ is the dose from the contributions of dosimetry, quality assurance and maintenance of the linear accelerator. 
- $\mathrm{W}_{\text {sca: }}$ Determined by the dose at the isocenter received by the patient or phantom. One can consider conservatively: [3]

$$
\mathrm{W}_{\text {sca }}(\mathrm{QX})=\mathrm{W}_{\text {dir }}(\mathrm{QX})
$$

- $\mathrm{W}_{\text {leak }}$ : Determined from the total monitor units rendered per week and converted to dose by a conversion factor (1cGy/UM). [3]

$$
\mathrm{W}_{\text {leak }}(\mathrm{QX})=\mathrm{W}_{\mathrm{MU}, \text { conv }}(\mathrm{QX})+\mathrm{W}_{\mathrm{MU}, \bmod }(\mathrm{QX})+\mathrm{W}_{\mathrm{MU}, \text { phy }}(\mathrm{QX})
$$

Where $\mathrm{W}_{\mathrm{MU}}$ is the workload in terms of the total monitor units delivered with a given technique.

The leakage workload can also be written as follows:

$$
\mathrm{W}_{\text {leak }}(\mathrm{QX})=\mathrm{C}_{\text {conv }} * \mathrm{~W}_{\mathrm{D}, \text { conv }}(\mathrm{QX})+\mathrm{C}_{\text {mod }} * \mathrm{~W}_{\mathrm{D}, \bmod }(\mathrm{QX})+\mathrm{C}_{\text {phy }} * \mathrm{~W}_{\mathrm{D}, \text { phy }}(\mathrm{QX})
$$

Where $\mathrm{C}$ is a factor used to take into account the contributions of different techniques to leakage radiation and which can be determined using the following equations:

$$
\begin{aligned}
\mathrm{C}_{\text {conv }} & =\mathrm{W}_{\mathrm{MU}, \text { conv }}(\mathrm{QX}) / \mathrm{W}_{\mathrm{D}, \text { conv }}(\mathrm{QX}) \\
\mathrm{C}_{\text {mod }} & =\mathrm{W}_{\mathrm{MU}, \bmod }(\mathrm{QX}) / \mathrm{W}_{\mathrm{D}, \bmod }(\mathrm{QX}) \\
\mathrm{C}_{\text {phy }} & =\mathrm{W}_{\mathrm{MU}, \text { phy }}(\mathrm{QX}) / \mathrm{W}_{\mathrm{D}, \text { phy }}(\mathrm{QX})
\end{aligned}
$$

Use Factor (U): Fraction of a primary beam workload that is directed toward a given primary barrier.

Occupancy Factor (T): Average fraction of time that the maximally exposed individual is present while the beam is on.

Dose Limit (P): Effective dose limit for the point to be protected. It is established by CNEN in the national norm NN-3.01 [8], for the general public as $1 \mathrm{mSv} / \mathrm{year}$.

Primary Barrier: Barrier that intercepts the radiation emitted directly from the source.

Secondary Barrier: Barrier that intercepts the secondary radiation (leakage radiation emitted by the head and radiation scattered by the patient and other objects.

Thus, the barriers calculation consists of, starting from the effective dose $(\mathrm{H})$ that reaches the point where it is desired to protect in the absence of a barrier and the dose limit $(\mathrm{P})$ established in a national norm, determining the optimal transmission (B) and, through this transmission, calculate the number of tenth-value layers (TVL) necessary to achieve such transmission and, finally, the desired thickness (t). That is:

$$
\mathrm{B}=\mathrm{P} / \mathrm{H} \rightarrow \mathrm{n}=-\log _{10} \mathrm{~B} \rightarrow \mathrm{t}=\mathrm{TVL}_{1}+(\mathrm{n}-1) * \mathrm{TVL} \text { eq }
$$


Where $\mathrm{TVL}_{1}$ is the first tenth-value layer and TVLeq is the equilibrium tenth-value layer, used for thicknesses greater than $\mathrm{TVL}_{1}$ in order to take into account the spectral changes of the beam when crossing the first tenth-value layer.

For accelerators with two energies (HE - high-energy and LE - low-energy), such as the 2100CD, a separate calculation must be performed for each energy, which will result in two thicknesses: $t(H E)$ and $t(L E)$. The combination of the two thicknesses is done as follows:

- If $|\mathrm{t}(\mathrm{HE})-\mathrm{t}(\mathrm{LE})|<1 \mathrm{TVL}(\mathrm{HE})$, then a half-value layer of the most penetrating source HVL(HE) should be added to the largest thickness ( $t(H E)$ or $t(L E)$ );

- Otherwise:

- If $\mathrm{t}(\mathrm{LE})>\mathrm{t}(\mathrm{HE})+\mathrm{TVL}(\mathrm{HE})$, use $\mathrm{t}(\mathrm{LE})$;

-If $\mathrm{t}(\mathrm{HE})>\mathrm{t}(\mathrm{LE})+\mathrm{TVL}(\mathrm{LE})$, use $\mathrm{t}(\mathrm{HE})$.

\subsubsection{Primary Barrier}

For the primary barrier, the calculation of the optimal transmission $\left(\mathrm{B}_{\text {prim }}\right)$ is performed through the following equation [2]:

$$
\mathrm{B}_{\text {prim }}=\left[\mathrm{P} *\left(\mathrm{~d}_{\text {prim }}\right)^{2}\right] /\left[\mathrm{W}_{\mathrm{dir}} * \mathrm{U} * \mathrm{~T}\right]
$$

Where $\mathrm{d}_{\text {prim }}$ is the distance in meters between the X-ray target and the point to be protected.

\subsubsection{Secondary Barrier - Scattering}

For the secondary scattering barrier, the calculation of the optimal transmission $\left(\mathrm{B}_{\text {sca }}\right)$ is performed through the following equation [2]

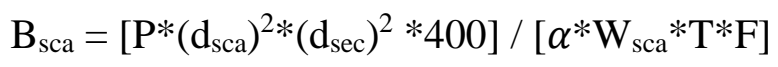

Where $d_{\text {sca }}$ is the distance in meters between the X-ray target and the spreading surface, $d_{\text {sec }}$ is the distance between the spreading surface and the point to be protected, $\alpha$ is the ratio between the intensity of the scattered radiation at a distance of $1 \mathrm{~m}$ from the scattering medium and the intensity of the primary radiation at the isocenter and is a function of the beam energy and the scattering angle, $\mathrm{F}$ is the size of the field in the patient in $\mathrm{cm}^{2}$ and 400 assumes that the scattering fractions are normalized to those measured for a field of size $(20 \times 20) \mathrm{cm}^{2}$. 


\subsubsection{Secondary Barrier - Leakage}

For the secondary leakage barrier, the calculation of the optimal transmission ( $B_{\text {leak }}$ ) is performed through the following equation [2]:

$$
\mathrm{B}_{\text {leak }}=\left[1000 * \mathrm{P} *\left(\mathrm{~d}_{\text {leak }}\right)^{2}\right] /\left[\mathrm{W}_{\text {leak }} * \mathrm{~T}\right]
$$

Where 1000 is the head's attenuation factor, assuming the leakage radiation in the head is $0.1 \%$ and $d_{\text {leak }}$ is the distance in meters between the isocenter and the point to be protected.

The final thickness of the secondary barrier is calculated through the procedure described previously for the combination of two thicknesses calculated for sources of different energies, considering that the leakage radiation is more penetrating than the scattered radiation.

\subsubsection{Door}

For high-energy accelerators (greater than $10 \mathrm{MV}$ ), three components must be considered for the dose that arrives at the maze's door: Нтот (scattered and leakage radiation photons); $\mathrm{H}_{\mathrm{CG}}$ (neutron capture gamma rays), and $\mathrm{H}_{\mathrm{N}}$ (neutrons).

The first component $\left(\mathrm{H}_{\mathrm{TOT}}\right)$ can be taken into account as the sum of four contributions [2]:

- $\mathrm{H}_{\mathrm{S}}$ : dose equivalent per week due to scattering of the primary beam from the room surfaces;

- $\mathrm{H}_{\mathrm{LS}}$ : dose equivalent per week due to head-leakage photons scattered by the room surfaces;

- HPs: dose equivalent per week due to primary beam scattered from the patient;

- $\mathrm{H}_{\mathrm{LT}}$ : dose equivalent per week due to leakage radiation which is transmitted through the inner maze wall.

Thus, the sum of the contributions of the doses generated by the scattered and leakage radiation at the door is given by [2]:

$$
\mathrm{H}_{\mathrm{G}}=\mathrm{f}^{*} \mathrm{H}_{\mathrm{S}}+\mathrm{H}_{\mathrm{LS}}+\mathrm{H}_{\mathrm{PS}}+\mathrm{H}_{\mathrm{LT}}
$$

Where $\mathrm{f}$ is the fraction of radiation that is transmitted through the patient.

Lastly, the total dose due to the contribution of the incidences on all walls is given by [2]:

$$
\mathrm{H}_{\mathrm{TOT}}=2.64 * \mathrm{H}_{\mathrm{G}}
$$

The second component $\left(\mathrm{H}_{\mathrm{CG}}\right)$ is due to the neutron capture gamma rays and can be obtained through the following equation:

$$
\mathrm{H}_{\mathrm{CG}}=\mathrm{W}_{\text {leak, }} 15 \mathrm{MV} * \mathrm{~h}_{\varphi}
$$




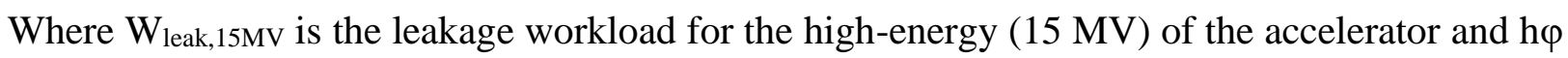
is the equivalent dose due to neutron capture gamma rays, outside the door, per unit of absorbed dose of X-rays in the isocenter.

The third component $\mathrm{H}_{\mathrm{N}}$ can be determined using Kersey's method (1979) [2], which assumes that the position of the neutron source is the isocenter of the linear accelerator and the weekly equivalent dose at the door due to neutrons can be described by:

$$
\mathrm{H}_{\mathrm{N}}=\mathrm{W}_{\text {leak, }} 15 \mathrm{MV} * \mathrm{H}_{\mathrm{N}, \mathrm{D}}
$$

Where $\mathrm{H}_{\mathrm{N}, \mathrm{D}}$ is the equivalent dose at the door due to neutrons per unit of absorbed $\mathrm{X}$-ray dose at the isocenter.

To attenuate the different dose components that arrive at the door, it is necessary to consider which is the most suitable material to shield such components (lead in the case of $\mathrm{H}_{\mathrm{TOT}}$ and $\mathrm{H}_{\mathrm{CG}}$ and polyethylene in the case of $\mathrm{H}_{\mathrm{N}}$ ). In this way, it is possible to separately determine the thickness of each material for each component:

- Lead thickness required to shield $\mathrm{H}_{\mathrm{TOT}}\left(\mathrm{t}_{\mathrm{TOT}}\right)$ :

$$
\mathrm{B}_{\mathrm{TOT}}=\mathrm{P} / \mathrm{H}_{\mathrm{TOT}} \rightarrow \mathrm{n}=-\log _{10} \mathrm{~B}_{\mathrm{TOT}} \rightarrow \mathrm{t}_{\mathrm{TOT}}=\mathrm{n}^{*} \mathrm{TVL} \mathrm{TOT}_{\mathrm{T}}
$$

Where $\mathrm{B}_{\text {тот }}$ is the optimal transmission calculated for the $\mathrm{H}_{\text {тот }}$ component of the door dose and TVL $_{\text {Tот }}$ is the lead tenth-value layer for the scattered and leakage photon energy in the order of 0.5 $\mathrm{MeV}\left(\mathrm{TVL}_{\mathrm{TOT}} \cong 0.5 \mathrm{~cm}\right)$.

- Lead thickness required to shield $\mathrm{H}_{\mathrm{CG}}\left(\mathrm{t}_{\mathrm{CG}}\right)$ :

$$
\mathrm{B}_{\mathrm{CG}}=\mathrm{P} / \mathrm{H}_{\mathrm{CG}} \rightarrow \mathrm{n}=-\log _{10} \mathrm{~B}_{\mathrm{CG}} \rightarrow \mathrm{t}_{\mathrm{CG}}=\mathrm{n} * \mathrm{TVL} \mathrm{LG}_{\mathrm{CG}}
$$

Where $\mathrm{B}_{\mathrm{CG}}$ is the optimal transmission calculated for the $\mathrm{H}_{\mathrm{CG}}$ component of the door dose and TVLCG is the lead tenth-value layer for the neutron capture gamma rays energy in the order of 3.6 $\mathrm{MeV}(\mathrm{TVL} \mathrm{CG} \cong 6.1 \mathrm{~cm})$.

- Polyethylene thickness required to shield $\mathrm{H}_{\mathrm{N}}\left(\mathrm{t}_{\mathrm{N}}\right)$ :

$$
\mathrm{B}_{\mathrm{N}}=\mathrm{P} / \mathrm{H}_{\mathrm{N}} \rightarrow \mathrm{n}=-\log _{10} \mathrm{~B}_{\mathrm{N}} \rightarrow \mathrm{t}_{\mathrm{N}}=\mathrm{n} * \mathrm{TVL}_{\mathrm{N}}
$$

Where $\mathrm{B}_{\mathrm{N}}$ is the optimal transmission calculated for the $\mathrm{H}_{\mathrm{N}}$ component of the door dose and $\mathrm{TVL}_{\mathrm{N}}$ is the polyethylene tenth-value layer for the neutron energy in the order of $0.1 \mathrm{MeV}(\mathrm{TVL} \cong$ $4.5 \mathrm{~cm})$. 


\section{RESULTS AND DISCUSSION}

Tables 1 and 2 show clinical workload data in terms of dose per week $\left(\mathrm{W}_{\mathrm{D}}\right)$ and monitor units per week ( $\mathrm{W}_{\mathrm{MU}}$ ) for the years of 2010 to 2015 (Clinac 2100C) and, after the upgrade, for the years of 2016 to 2020 (Clinac 2100 CD). These data are separated for conventional (6 MV, $15 \mathrm{MV}$, and electrons) and modulated (6 MV) techniques, extracted from the management software. For the calculation, it was considered that each complete year has fifty weeks and, for the years that did not have data for all twelve months, the result obtained was divided by the corresponding number of weeks.

Table 1: Weekly clinical workload in terms of dose $W_{D}(G y / w k)$ and in terms of monitor units $\mathrm{W}_{\mathrm{MU}}(\mathrm{Gy} / \mathrm{wk})$ for the $2100 \mathrm{C}$.

\begin{tabular}{ccccccc}
\hline & \multicolumn{2}{c}{ 6 MV } & \multicolumn{2}{c}{ 15 MV } & \multicolumn{2}{c}{ Electrons } \\
\cline { 2 - 7 } Year & $\mathbf{W}_{\mathbf{M U}}$ & WD & $\mathbf{W M U}_{\mathbf{M U}}$ & $\mathbf{W D}_{\mathbf{D}}$ & $\mathbf{W}_{\mathbf{M U}}$ & $\mathbf{W}_{\mathbf{D}}$ \\
\hline 2010 & 141 & 120 & 278 & 195 & 63 & 45 \\
2011 & 317 & 264 & 332 & 234 & 123 & 91 \\
2012 & 476 & 354 & 145 & 105 & 120 & 89 \\
2013 & 520 & 382 & 161 & 99 & 142 & 106 \\
2014 & 490 & 317 & 205 & 135 & 84 & 63 \\
2015 & 921 & 587 & 184 & 117 & 71 & 54 \\
\hline
\end{tabular}

Table 2: Weekly clinical workload in terms of dose $W_{D}(G y / w k)$ and in terms of monitor units $\mathrm{W}_{\mathrm{MU}}(\mathrm{Gy} / \mathrm{wk})$ for the $2100 \mathrm{CD}$.

\begin{tabular}{ccccccccc}
\hline & \multicolumn{2}{c}{ 6 MV } & \multicolumn{2}{c}{ 6 MV - mod } & \multicolumn{2}{c}{$\mathbf{1 5} \mathbf{M V}$} & \multicolumn{2}{c}{ Electrons } \\
\cline { 2 - 8 } Year & $\mathbf{W}_{\mathbf{M U}}$ & $\mathbf{W}_{\mathbf{D}}$ & $\mathbf{W}_{\mathbf{M U}}$ & $\mathbf{W}_{\mathbf{D}}$ & $\mathbf{W}_{\mathbf{M U}}$ & $\mathbf{W}_{\mathbf{D}}$ & $\mathbf{W}_{\mathbf{M U}}$ & $\mathbf{W}_{\mathbf{D}}$ \\
\hline 2016 & 480 & 377 & 82 & 19 & 86 & 67 & 40 & 31 \\
2017 & 258 & 200 & 334 & 126 & 78 & 58 & 29 & 21 \\
2018 & 162 & 128 & 677 & 248 & 66 & 51 & 21 & 15 \\
2019 & 83 & 65 & 579 & 211 & 36 & 28 & 23 & 17 \\
2020 & 55 & 43 & 996 & 346 & 35 & 28 & 5 & 4 \\
\hline
\end{tabular}


Through the workload data in terms of dose $\left(\mathrm{W}_{\mathrm{D}}\right)$ and in terms of monitor units $\left(\mathrm{W}_{\mathrm{MU}}\right)$ extracted from the system, it is possible to determine the "C factor" (equations 5 to 7), updated for the casuistry of the techniques performed in the institution, which in this article was used to consider the contribution of the total monitor units delivered in increasing the leakage workload. Figure 2 shows the data found for $\mathrm{C}$ during the years of 2010 to 2015 (2100C) and during the years of 2016 to 2020 (2100CD).
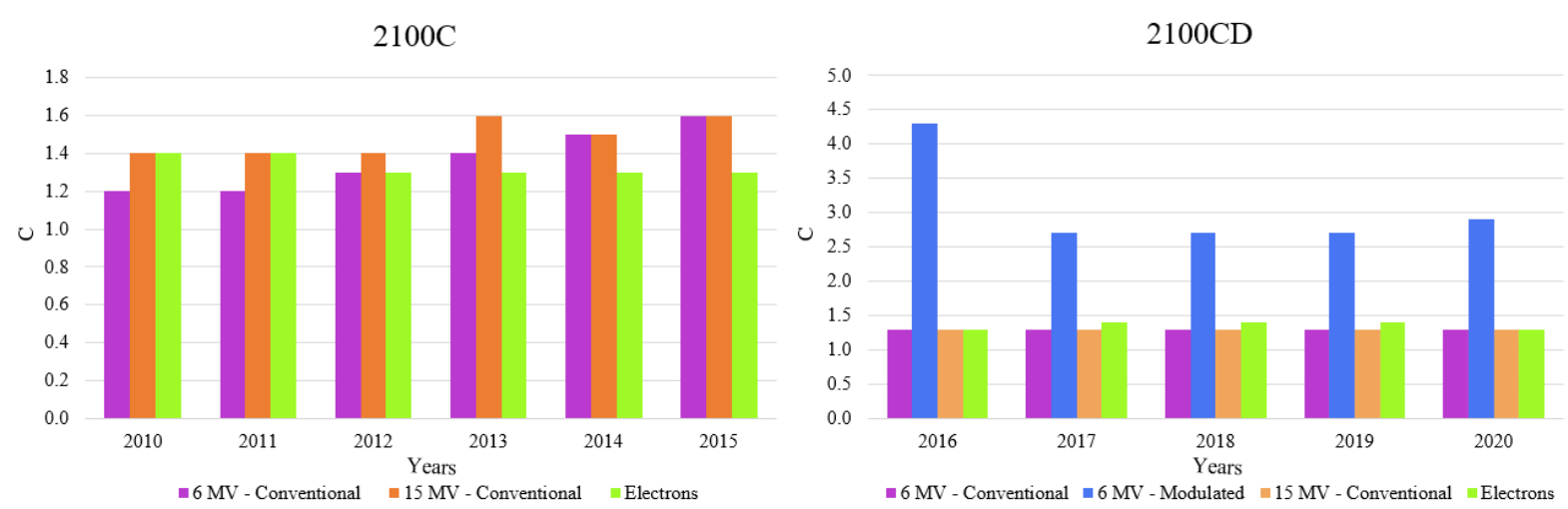

Figure 2: C factor for different techniques over the years 2010 to 2015 (2100C) and 2016 to 2020 (2100CD).

Through the figures, it is observed that for conventional techniques the highest value found for C was 1.6 (2013 and 2015) and the lowest value found was 1.2 (2010 and 2011). For the modulated techniques, the highest value found was 4.3 (2016) and the lowest value found was 2.7 (2017, 2018, and 2019). The high value of 2016, which stands out from those found for the following years, is because in $2016,46 \%$ of the patients who were treated with intensity modulated techniques used IMRT and, as of the end of 2016, 99\% of the patients who were treated with modulated intensity used VMAT.

Separating the clinical workload encountered for the intensity-modulated techniques in the year of 2016 between IMRT and VMAT, it is possible to calculate the C factor separately for each of these techniques, in order to highlight the difference between them in terms of shielding. Thus, in the year of 2016, for the IMRT and VMAT techniques, a C factor of 5.0 and 3.2 were found, respectively. This may be related to the fact that with the VMAT technique only one or two arcs are used in comparison to the large number of fields used with IMRT, promoting a reduction in the total 
number of monitor units. [9-11] All $\mathrm{C}$ values found are less than or equal to those used in the estimation for the shielding calculation $(\mathrm{C}=5)$.

Next, in tables 3 and 4, the weekly physical workload data determined for the 2100C and $2100 \mathrm{CD}$ are presented.

Table 3: Weekly physical workload in terms of dose $W_{D}(\mathrm{~Gy} / \mathrm{wk})$ and in terms of monitor units $\mathrm{W}_{\mathrm{MU}}(\mathrm{Gy} / \mathrm{wk})$ for the $2100 \mathrm{C}$.

\begin{tabular}{ccccc}
\hline & \multicolumn{3}{c}{ 6 MV } & \multicolumn{2}{c}{ 15 MV } \\
\cline { 2 - 6 } Year & WMU & WD & WMU & W D \\
\hline $2010-2015$ & 133 & 133 & 60 & 60 \\
\hline
\end{tabular}

Table 4: Weekly physical workload in terms of dose $W_{D}(\mathrm{~Gy} / \mathrm{wk})$ and in terms of monitor units $\mathrm{W}_{\mathrm{MU}}(\mathrm{Gy} / \mathrm{wk})$ for the 2100CD.

\begin{tabular}{ccccc}
\hline & \multicolumn{2}{c}{ 6 MV } & \multicolumn{2}{c}{ 15 MV } \\
\cline { 2 - 5 } Year & $\mathbf{W}_{\mathbf{M U}}$ & $\mathbf{W}_{\mathbf{D}}$ & $\mathbf{W}_{\mathbf{M U}}$ & $\mathbf{W}_{\mathbf{D}}$ \\
\hline 2016 & 166 & 141 & 60 & 60 \\
2017 & 199 & 154 & 60 & 60 \\
2018 & 234 & 166 & 60 & 60 \\
2019 & 236 & 167 & 60 & 60 \\
2020 & 228 & 163 & 60 & 60 \\
\hline
\end{tabular}

It is observed that only in the case of the $2100 \mathrm{CD}$, for the energy of $6 \mathrm{MV}$, there are differences between the workloads in terms of dose and in terms of monitor units. This is because only for data extracted directly from the management software it is possible to make this distinction. In the case of the estimates made to determine the physical workload, it was considered that $\mathrm{W}_{\mathrm{D}}=\mathrm{W}_{\mathrm{MU}}$.

Through the data extracted from the equipment for clinical and physical workload and disregarding the electron workload data, as recommended by NCRP 151 [2], it was possible to redo the shielding calculation at the points shown in figure 3.

The thickness results calculated for each year, as well as the thicknesses existing in the room, can be seen in table 5 . 


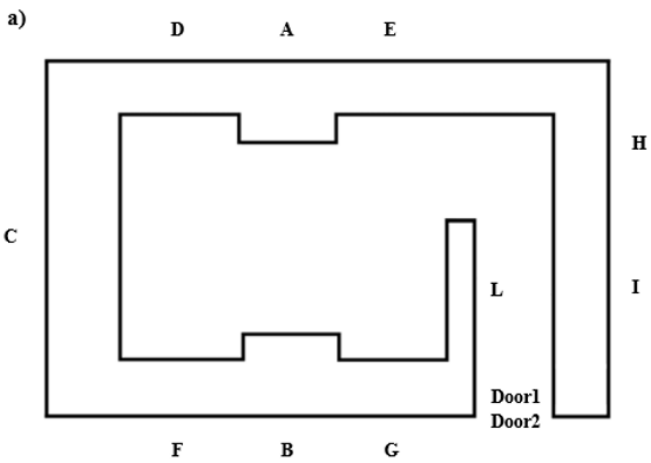

b)

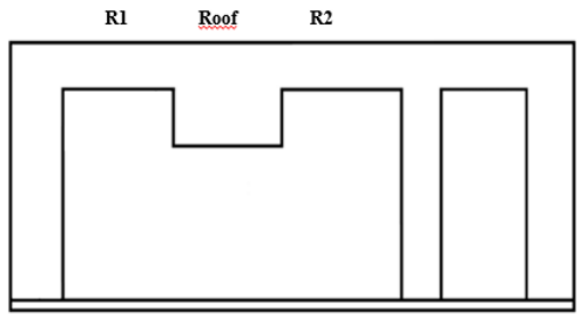

Figure 3: a) Cross-section and b) longitudinal section of the treatment room. Points $A, B$, and Roof correspond to the primary barriers, points $C, D, E, F, G, H, I, L, R 1$, and $R 2$ to the secondary barriers, and Door1 and Door2 correspond to the lead and polyethylene thickness of the door, respectively.

Source: Adapted from NCRP 151 [2], with permission of the National Council on Radiation Protection and Measurements, https://NCRPonline.org.

Table 5: Thicknesses $(\mathrm{cm})$ calculated through the workload found from the accelerators $2100 \mathrm{C}$ and $2100 \mathrm{CD}$, as well as the thicknesses currently existing in the room.

\begin{tabular}{|c|c|c|c|c|c|c|c|c|c|c|c|c|}
\hline \multirow[b]{2}{*}{ Place } & \multirow[b]{2}{*}{ Current } & \multicolumn{6}{|c|}{$2100 \mathrm{C}$} & \multicolumn{5}{|c|}{$2100 \mathrm{CD}$} \\
\hline & & 2010 & 2011 & 2012 & 2013 & 2014 & 2015 & 2016 & 2017 & 2018 & 2019 & 2020 \\
\hline $\mathrm{A}$ & 160 & 128 & 138 & 131 & 131 & 133 & 132 & 128 & 128 & 127 & 124 & 124 \\
\hline B & 160 & 128 & 138 & 131 & 131 & 133 & 132 & 128 & 128 & 127 & 124 & 124 \\
\hline Roof & 165 & 102 & 103 & 97 & 96 & 99 & 98 & 94 & 93 & 92 & 90 & 90 \\
\hline $\mathrm{C}$ & 135 & 72 & 75 & 76 & 77 & 76 & 72 & 78 & 68 & 72 & 70 & 75 \\
\hline $\mathrm{D} / \mathrm{E}$ & 125 & 96 & 98 & 91 & 91 & 92 & 95 & 92 & 91 & 92 & 90 & 87 \\
\hline $\mathrm{L}$ & 100 & 71 & 73 & 73 & 74 & 74 & 80 & 76 & 77 & 80 & 78 & 83 \\
\hline $\mathrm{F} / \mathrm{G}$ & 125 & 114 & 110 & 108 & 108 & 104 & 111 & 108 & 106 & 108 & 105 & 108 \\
\hline $\mathrm{H}$ & 138 & 63 & 65 & 68 & 68 & 68 & 74 & 70 & 71 & 75 & 72 & 77 \\
\hline I & 135 & 107 & 109 & 107 & 108 & 107 & 114 & 109 & 110 & 114 & 112 & 116 \\
\hline $\mathrm{R} 1 / \mathrm{R} 2$ & 130 & 93 & 95 & 88 & 89 & 89 & 82 & 90 & 88 & 90 & 87 & 90 \\
\hline Door1 & 6 & 5 & 6 & 4 & 4 & 5 & 5 & 3 & 3 & 3 & 2 & 2 \\
\hline Door2 & 16 & 13 & 14 & 12 & 13 & 13 & 13 & 12 & 12 & 11 & 11 & 11 \\
\hline
\end{tabular}


Through the results observed in table 5 , it is confirmed that the calculation of barriers is overestimated for most points. There is also a tendency in decreasing the thickness of the primary barriers when the intensity-modulated techniques are introduced and used more frequently. This is because it was established by the institution that techniques such as IMRT and VMAT would only be performed with $6 \mathrm{MV}$, thus promoting a decrease in the use of $15 \mathrm{MV}$ energy, that is, a reduction in the high-energy workload and, consequently, a decrease in the calculated thickness for the primary barrier.

Little variation was observed, however, in the thickness of secondary barriers due to the fact that, although the leakage workload has increased for the $6 \mathrm{MV}$ energy, the leakage workload for the $15 \mathrm{MV}$ energy has decreased, resulting in a not very expressive variation in thickness. This is exemplified below through the thicknesses calculated for the secondary barrier $\mathrm{C}$ in the years of 2010 (before the clinac upgrade period) and 2018 (after the clinac upgrade).

Table 5 shows the final values obtained for the secondary barrier. Explaining the calculation, in 2010, the thicknesses calculated for the secondary leakage barrier for high-energy and low-energy at point $\mathrm{C}$ were:

- $\mathrm{t}_{\text {leak }}(\mathrm{HE})=51 \mathrm{~cm}$;

$\bullet_{\text {leak }}(\mathrm{LE})=44 \mathrm{~cm}$;

Combining these two thicknesses as described in the methodology, we find for the secondary leakage barrier $\mathrm{t}_{\text {leak }}=62 \mathrm{~cm}$ which, combined with the thickness found for the secondary scattering barrier at this point $\left(\mathrm{t}_{\mathrm{sca}}=30 \mathrm{~cm}\right)$, results in the final thickness for the secondary barrier of $72 \mathrm{~cm}$. Likewise, in 2018:

- $\mathrm{t}_{\text {leak }}(\mathrm{HE})=37 \mathrm{~cm}$;

- $\mathrm{t}_{\text {leak }}(\mathrm{LE})=61 \mathrm{~cm}$;

Combining these two thicknesses, it is found for the secondary leakage barrier $t_{\text {leak }}=72 \mathrm{~cm}$ which, combined with the thickness found for the secondary scattering barrier at this point $\left(\mathrm{t}_{\mathrm{sca}}=34\right.$ $\mathrm{cm})$ results in the final thickness for the secondary barrier of $72 \mathrm{~cm}$.

That is, although the workload in terms of monitor units for $6 \mathrm{MV}$ increased from $274 \mathrm{~Gy} / \mathrm{wk}$ in 2010 to $1073 \mathrm{~Gy} / \mathrm{wk}$ in 2018 and impacted on an increase in the thickness found for the secondary low-energy leakage barrier from $44 \mathrm{~cm}$ to $61 \mathrm{~cm}$, the workload in terms of monitor units for $15 \mathrm{MV}$ 
decreased from 338 Gy/wk to 126 Gy/wk, impacting a reduction in the thickness found for the secondary high-energy leakage barrier from $51 \mathrm{~cm}$ to $37 \mathrm{~cm}$. Thus, the thicknesses for barrier C calculated for the two selected years resulted in the same value.

Another data that can be extracted from the management software is the number of patients treated per year. The average with its respective standard deviation number of patients treated annually in the period from 2010 to 2020 was $(465 \pm 71)$ patients, with the highest and lowest number of treated patients: 642 and 379, in 2015 and 2019, respectively. The lowest value found for the year of 2019 may be related to the interruption of the treatments in the linear accelerator for corrective maintenance during a month.

The number of patients treated with each technique (modulated - $6 \mathrm{MV}$, conventional - $6 \mathrm{MV}$, conventional - $15 \mathrm{MV}$, and electrons) was also extracted, in order to understand the treatment profile at the institution and how it has changed over time. Figures 4 and 5 present this information.

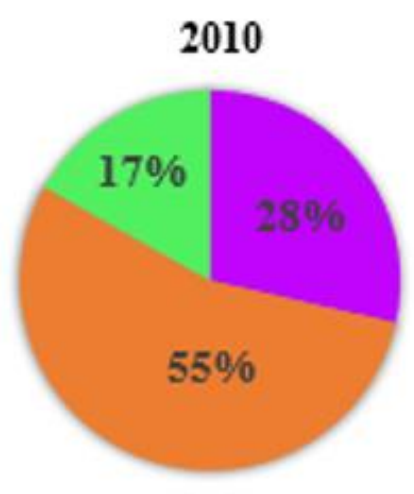

2013

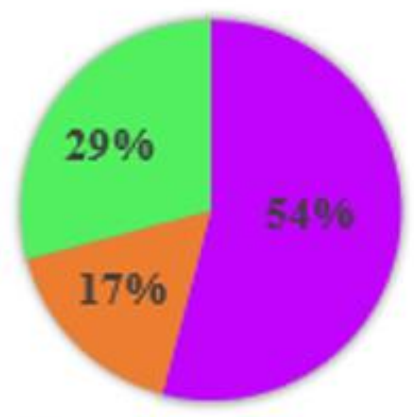

- $6 \mathrm{MV}$ - Conventional
2011

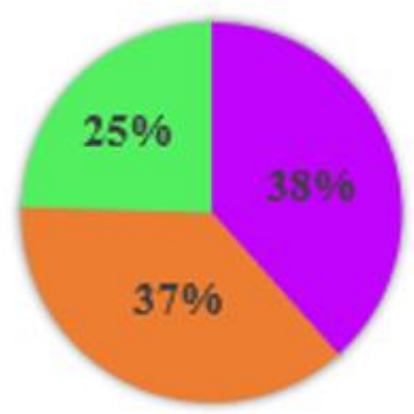

2014

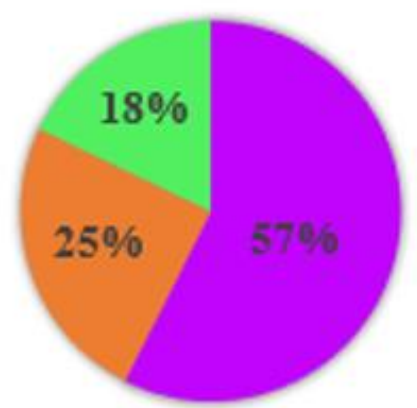

=15 MV - Conventional
2012

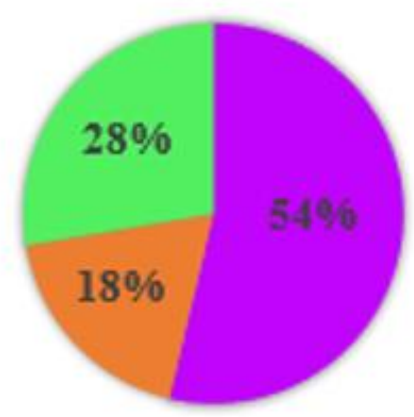

2015

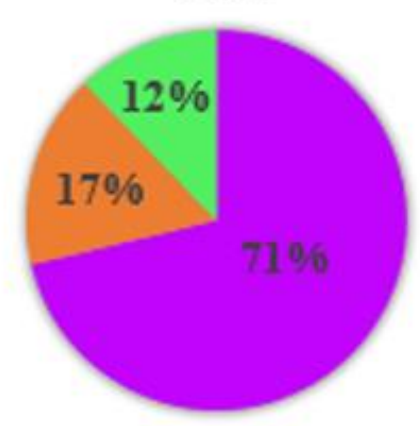

Electrons

Figure 4: Proportion of patients treated with different techniques in the 2100C, divided between conventional techniques with photons (6 MV and 15 MV) and electrons, from 2010 to 2015. 
2016

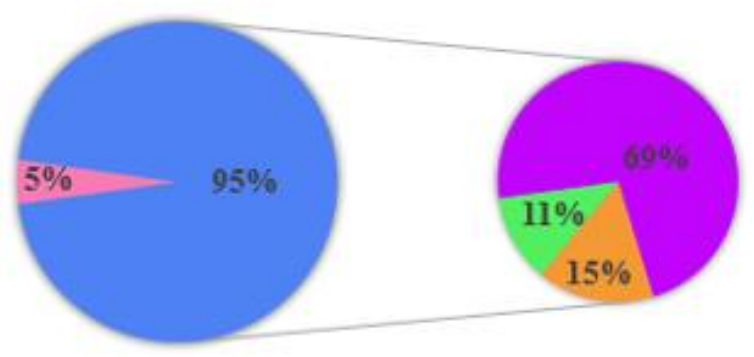

2018

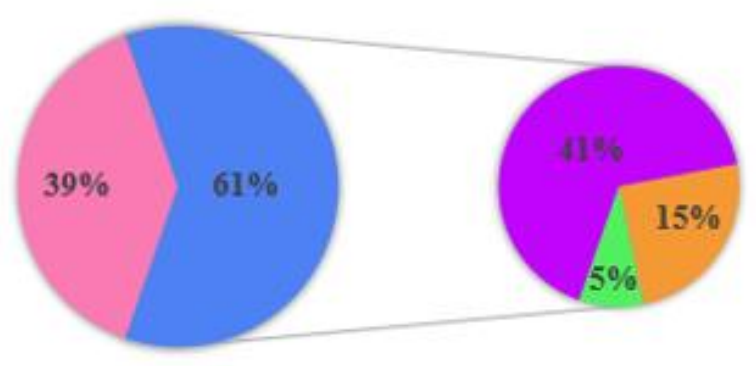

2017

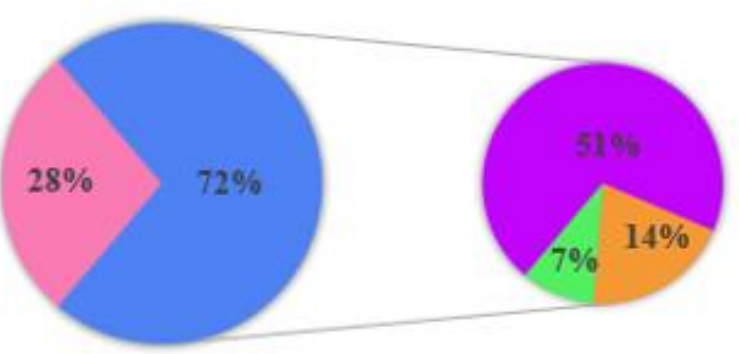

2019

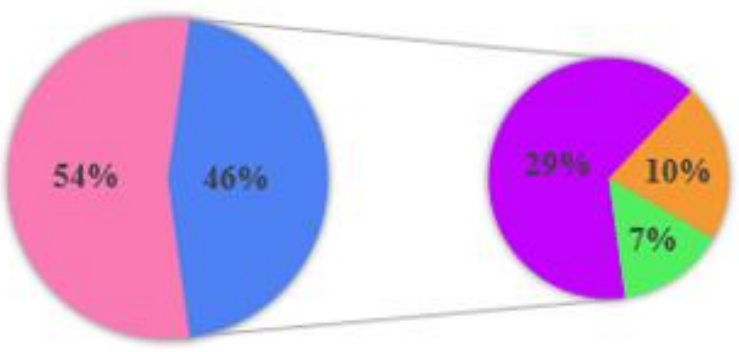

2020

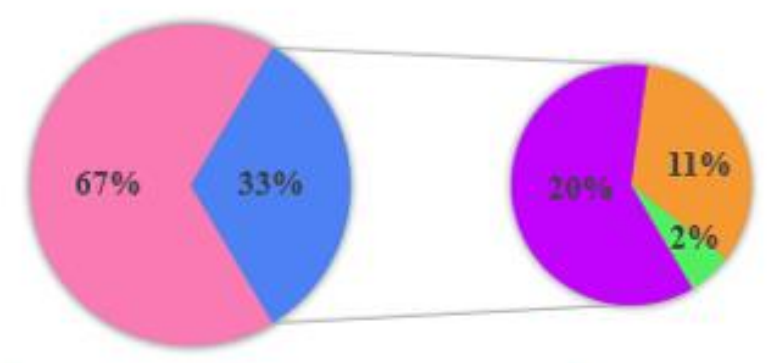

$=6 \mathrm{MV}$ - Modulated $=$ Conventional $=6 \mathrm{MV}$ - Conventional $=15 \mathrm{MV}$ - Conventional $=$ Electrons

Figure 5: Proportion of patients treated with different techniques in the 2100CD, divided between techniques modulated with photons (6 MV), conventional with photons (6 MV and $15 \mathrm{MV}$ ), and electrons, from 2016 to 2020.

Through the figures, it is noticeable a change in the techniques profile carried out over the years. For the $2100 \mathrm{C}$, at first, treatments were performed mostly with the energy of $15 \mathrm{MV}(55 \%)$, but this profile changed over time, and in doing so, in 2015 only $17 \%$ of patients were treated with this energy.

The percentage of patients treated with $15 \mathrm{MV}$ remained approximately constant (between $10 \%$ and $15 \%$ ) after the implementation of intensity-modulated techniques. The biggest change was concerning the treatments done with the energy of $6 \mathrm{MV}$, which initially were mostly conventional techniques (69\%), but year after year gave way to the IMRT and VMAT techniques, which currently represent the techniques used in $67 \%$ of patients. 


\section{CONCLUSION}

The analysis of the data extracted from the management software allows the conclusion that the value of $\mathrm{C}=5$, generally used for the barriers calculation when intensity-modulated techniques are used, is adequate, in the case of IMRT, since what was observed in the institution was 5.0 when only this modulation technique was used, but considering the VMAT technique it would be overestimated since the value observed for this type of treatment was of the order of 2.7.

Although intensity-modulated techniques were included, the accelerator does not have accessories for the acquisition of volumetric images, such as OBI (On-Board Imaging), and does not perform hypofractionated treatments and complex techniques such as SBRT and SRS. Thus, the change observed in the thickness of the primary barriers calculated before and after the introduction of IMRT/VMAT is solely due to the reduction of the high-energy workload (15 MV). Such reduction also made it possible that the thickness of the secondary barriers did not undergo significant variations, despite the increase in the low energy leakage workload (6 MV).

Knowing the treatment profile performed at the institution allows to critically evaluate the estimates used in the calculation and, possibly, to use more suitable values for future calculations, enabling, for example, optimization processes for barrier calculation.

Furthermore, understanding the impact that different techniques have on the thicknesses calculated for the barriers allows us to analyze atypical situations found in the service, such as, for example, an extension of the daily treatment period, or a change in the proportion of patients treated with high-energy due to the maintenance of another machine, among others. In addition to enabling the submission of reports evaluating these new situations for the regulatory agency. In this sense, it would be possible to analyze the results of the radiometric survey carried out every two years, also based (in addition to the workload initially estimated) on the current workload, which may result in relevant observations regarding the current clinical practice of the accelerator, thus ensuring the safety of the occupationally exposed individual as well as the country regulations. 


\section{ACKNOWLEDGMENT}

To the Ministry of Health (SGTES) and the Ministry of Education (SESu) for the financial support granted during the residency period.

\section{REFERENCES}

[1] NCRP 49: Structural Shielding Design and Evaluation for Medical Use of X-Rays and GammaRays up to $10 \mathrm{MeV}$.

[2] NCRP 151: Structural shielding design and evaluation for megavoltage $x$-and gamma-ray radiotherapy facilities.

[3] Rodgers JE. Radiation therapy vault shielding calculational methods when IMRT and TBI procedures contribute. Journal of Applied Clinical Medical Physics. 2001;2(3):157-64.

[4] Mechalakos JG, Germain JS, Burman CM. Results of a one year survey of output for linear accelerators using IMRT and non-IMRT techniques. Journal of Applied Clinical Medical Physics. 2004;5(1):64-72.

[5] Mutic S, Low DA, Klein EE, Dempsey JF, Purdy JA. Room shielding for intensity-modulated radiation therapy treatment facilities. International Journal of Radiation Oncology Biology Physics.1o de maio de 2001;50(1):239-46.

[6] Price RA, Chibani O, Ma C-M. Shielding evaluation for IMRT implementation in an existing accelerator vault. Journal of Applied Clinical Medical Physics. 2003;4(3):231-8.

[7] Reis Junior, J. P., V. G. L. Alves, and L. R. Fairbanks. Total Workload for Radiotherapy Facilities with Volumetric Modulated Arc Treatment. Brazilian Journal of Radiation Sciences. 2019; 7(3): 1-13.

[8] Norma, CNEN. NE-3.01: Diretrizes Básicas de Proteção Radiológica.

[9] Ali, Arif N., et al. "Dosimetric comparison of volumetric modulated arc therapy and intensitymodulated radiation therapy for pancreatic malignancies." Medical Dosimetry 37.3 (2012): 271275.

[10] Lafond, C., et al. "Quelle RCMI? Du «step and shoot» au VMAT: point de vue du physicien." Cancer/Radiothérapie 14.6-7 (2010): 539-549.

[11] Van Benthuysen, Liam, Lee Hales, and Matthew B. Podgorsak. "Volumetric modulated arc therapy vs. IMRT for the treatment of distal esophageal cancer." Medical Dosimetry 36.4 (2011): 404-409. 